\title{
Manyetik rezonans görüntüleme için uygulanan sedasyonun çocuklardaki etkinliği ve güvenilirliği
}

\author{
The efficacy and safety of sedation in children who undergone magnetic resonance \\ imaging
}

Halil Kocamaz, Mehmet Ali Taş

Gönderilme tarihi: 10.01 .2020

Kabul tarihi: 16.03 .2020

\section{Özet}

Amaç: Manyetik rezonans görüntüleme (MRG) görüntüleme için sedasyon uygulanan çocuklarda görülen komplikasyonları ve sedasyon için uygulanan ilaçların etkinliğini göstermeyi amaçladık.

Gereç ve yöntem: Çalışmaya sedasyon verilerek MRG yapılan çocuklar dâhil edildi. Sedasyon öncesi hastaların fizik muayenesi yapılarak, vital bulguları ve (oksijen saturasyonları) $\mathrm{SO}_{2}$ düzeyleri ölçüldü. Sedasyon düzeyi Ramsay sedasyon skoru ile berlirlendi. Sedasyonun etkinliği radyolog tarafından belirlenen MRG kalite ölçeği ile değerlendirildi. Uygulanan ilaçların türleri ve vücut ağırlığına göre dozları kayıt edilerek, etkinlikleri değerlendirildi. MRG sonrasında hastaların vital bulguları, $\mathrm{SO}_{2}$ ve komplikasyonları tekrar değerlendirildi. Tüm analizler için SPSS 12 programı kullanıldı.

Bulgular: Çalışmaya 112 hasta (E/K; 68/44) dâhil edildi. Hastaların ortalama yaşı 4,2ะ3,4 (3 ay-11 yaş) idi. 93 hastaya kraniyal MRG için sedasyon yapıldı. Sedasyon için 79 hastaya kloralhidrat, 9 hastaya midazolam, 7 hastaya klorpromazin, 21 hastaya antihistaminik ve 4 hastaya da ketamin uygulandı. Bazı hastaarda birden çok ilaç verilmişti. Antihistaminiklerin sedasyon yapıcı etkisi yetersiz bulundu. Sedasyonla ilişkili en yaygın görülen komplikasyon gastrointestinal irritasyondu. Yedi hasta (\%6) da MRG sonrasında ciddi hipoksi görüldü. Çoğunluğu 1 yaş altındaydı. MRG süresi ve kalp hızı arasında negatif bir ilişki saptandı.

Sonuç: Oral yolla sedasyon verilmesi gastrointestinal komplikasyonları artırmaktadır. Özellikle bir yaşın altındaki infantlar diğer çocuklara oranla MRG ile ilişkili sedasyon sonrasında hipoksiye daha yatkındır. Antihistaminiklerin sedasyon için etkisiz olduğu görülmüştür.

Anahtar kelimeler: Anestezi, bilinçli sedasyon, çocuk.

Kocamaz H, Taş MA. Manyetik rezonans görüntüleme için uygulanan sedasyonun çocuklardaki etkinliği ve güvenilirliği. Pam Tıp Derg 2020;13:357-362.

\begin{abstract}
Purpose: We aimed to reveal the complications and efficay of sedative drugs in children who sedatized for magnetic resonance imaging (MRI).

Material and method: The children who undergone MRI with sedation were included in the study. Before the procedure, vital signs and peripheric oxygen saturation $\left(\mathrm{SO}_{2}\right)$ of the patients were recorded. The level of sedation was determined by using Ramsay sedation score. The efficacy of sedation was determined by using the quality of MRI score which is voted by radiologist. The sedative agents for sedation is also recorded acording to dosage per body weight. At the end of procedure vital signs, compliactions and $\mathrm{SO}_{2}$ was reevaluated. All analysis of data was made by using SPSS 12.0 program.

Results: Totaly 112 patients $68(60 \%)$ male and $44(39 \%)$ were included in the study. The mean age of patients was 4.2 \pm 3.4 ( 3 month-11 years). Ninety three patients had sedation for cranial imaging. Drugs for patients sedation had as follows: 79 had chloralhydrate, 9 had midazolam, 7 had chlorpromazine, 21 had antihistaminic and 4 had ketamine. The most ineffective drug for sedation were antihistaminics. The most common complication was gastrointestinal irritation. Seven patients $(6 \%)$ had severe hypoxia after MRI procedure. Most of them were under 1 years old. There was a negative correlation between the duration of MRG and heart rate.

Conclusion: Oral administration of sedative agents may lead to gastrointestinal complications. Particularly the infants under one year old tends to develop hypoxia after MRI related sedation. Antihistaminic agents are ineffective for sedation.
\end{abstract}

Key words: Anesthesia, child, conscious sedation.

Kocamaz H, Taş MA. The efficacy and safety of sedation in children who undergone magnetic resonance imaging. Pam Med J 2020;13:357-362.

Halil Kocamaz, Dr. Öğr. Üye. Pamukkale Üniversitesi Tıp Fakültesi, Çocuk Gastroenterolojisi Bilim Dalı Denizli, Türkiye, e-posta: drkocamaz@ hotmail.com (orcid.org/0000-0002-3366-1695) (Sorumlu Yazar)

Mehmet Ali Taş, Prof. Dr. (Emekli Öğretim Üyesi), Dicle Üniversitesi Tıp Fakültesi, Çocuk Sağlığı ve Hastalıkları Anabilim Dalı, Dicle Üniversitesi Kampüsü, Sur-Diyarbakır, Türkiye, e-posta: malitas2164@gmail.com (orcid.org/0000-0001-9714-7188) 


\section{Giriş}

Tanısal tetkiklerin çeşitliliğinin artmasıyla birlikte ameliyathane dışı sedasyon uygulamaları çocuklarda daartmaktadır[1]. Manyetik rezonans görüntüleme(MRG) radyasyon içermediği için ve diğer görüntüleme yöntemlerine oranla anatomik yapı hakkında daha detaylı bilgi verdiği için pediatristler tarafından sıklıkla tercih edilmektedir [2]. MRG sırasında uygulanan sedasyonun amacı, hastanın hemodinamisini bozmadan anksiyete ve korkusunu azaltarak MRG kalitesini artırmak için hareketsiz kalmasını sağlamaktır [3]. MRG odasında hastayı yatak başı gözlemlemek mümkün olmadığından sedasyona ait komplikasyonların da tanınması diğer tanısal işlemlere göre daha güçtür. Bu nedenle MRG sırasında hızı uyanma ve minimum yan etki sağlayacak sedasyon ve anestezi teknikleri tercih edilmektedir. MRG sırasında çocuklarda sedasyon amacıyla kloralhidrat, ketamine, propofol, midazolam ve pentobarbital gibi farklı ilaçlar kullanılmaktadır [4]. İngiltere Ulusal Sağlık ve Klinik Mükemmellik Enstitüsü (NICE) rehberinde 15 kg'ın altındaki çocuklarda tanısal görüntüleme için kloralhidrat veya midazolam kullanılması önerilmektedir. Bu ajanlar uygun değilse güvenlik aralığı dar olan propofol, sevofluran gibi ajanların anestezist tarafından uygulanması önerilmektedir [5]. Kloralhidrat anestezi uzmanı olmayan hekimler tarafından düşük komplikasyon ve yüksek etkinliği nedeniyle MRG için sıklıkla tercih edilen bir ajandır [6]. Tanısal işlemlerin çoğunda sedasyonla ilişkili riskler düşükken MRG yapılan çocukların \%21'inde sedasyon komplikasyonlara neden olmaktadır. Bildirilen komplikasyonlar ve sedasyonla ilişkili durumlar arasında \%5,5 solunum sıkıntısı, \%13,1 aşırı sedasyon ve $\% 3,7$ yetersiz sedasyon bulunmaktadır [2].

$\mathrm{Bu}$ çalışmada MRG görüntüleme için sedasyon uygulanan çocuklarda ortaya çıkan komplikasyonları belirlemeyi ve MRG sonrasında vital bulgulardaki değişikliklerin önemini saptamayı amaçladık. Ayrıca sedasyon için uygulanan sedatif ajanların komplikasyonlarla ve MRG kalitesi, sedasyon skoru gibi parametrelerle ile ilişkilerini araştırdık.

\section{Gereç ve yöntem}

Çalışmaya Ocak-Haziran 2008 dönemleri arasında Dicle Üniversitesi Tıp Fakültesi Çocuk
Sağlığı ve Hastalıkları servisinde yatmakta olan ve sedasyon verilerek MRG yapılan çocuklar dâhil edildi. Hastaların işlem öncesinde ASA (American Society of Anesthesiology) skoru belirlendi [7]. Çalışmaya sadece ASA I ve ASA II sınıfındaki hastalar dâhil edildi. Hastalara sedasyon amacıyla verilen ilaçları hastayı takip eden çocuk doktoru tarafından uygulandı. Sedasyon ile MRG işlemi arasındaki süre ilacın etki süresi ve veriliş yoluna göre belirlendi. Kronik kalp, akciğer, karaciğer ve böbrek hastalığı olan, uyanıklığı etkileyecek ilaçlar kullanan veya bilinci bulanıklığı olan hastalar, ailede ilaç alerji öyküsü bulunan ve daha önce sedasyon almış çocuklar çalışma dışı bırakıldı. Sedasyon uygulanmadan 2 saat önce sıvı, 4 saat önce ise katı gıda alımı kesildi. Hastalara MRG öncesi sedasyon amacıyla verilecek ilacın türü ve veriliş yolu başlıca çocuk doktoru tarafından olmak üzere, radyoloji doktoru ve anestezi doktoru tarafından belirlendi. Uygulanan ilacın dozu $\mathrm{mg} / \mathrm{kg}$ olarak belirlendi ve ilacın uygulanma yolu kayıt edildi. İlaç uygulandıktan sonra ortaya çıkan komplikasyonlar varsa sistemlere göre belirlenip kayıt edildi. Sedasyon öncesi, hastaların dökümantasyonu yapılarak standart monitörizasyon işlemi ile sistolik kan basıncı (SKB), diastolik kan basıncı(DKB) , dakikadaki kalp tepe atımı sayısı (KTA) , periferik oksijen satürasyonu $\left(\mathrm{SO}_{2}\right)$ ve dakikadaki solunum sayısı (DSS) kaydedildi. Standart monitorizasyon işlemi için Petaş KMA 800, Serial No: 1804 cihazı ile yaşa uygun sensörler ve manşonlar kullanılarak ölçümler yapıldı. MRG işlemi bittikten sonra hastaların cilt ve sistemik muayenesi yapılarak, tüm vital bulguları, komplikasyonları ve $\mathrm{SO}_{2}$ değerleri tekrar kayıt edildi. Hastaların işlem sonrasında bakılan oksijen saturasyonları \%95 'in altına inmesi hipoksi \%92'nin altına inmesi ciddi hipoksi olarak kabul edildi. Sedasyon seviyesi sözlü, sesli emirler veya dokunmaya verilen yanıt ile değerlendirilerek Ramsay sedasyon skoru kullanılarak belirlendi [8].

Sedasyonun yeterli olup olmaması ve MRG'nin kalitesi radyoloji uzmanı tarafından aşağıdaki skalaya göre 4 puan üzerinden değerlendirildi:

- MRG kalitesi 1: Sedasyon çok iyi; hareket yok.

- MRG kalitesi 2: Sedasyon yeterli; minimal hareket var, ek ilaç gereksinimi olmadı. 
- MRG kalitesi 3: Sedasyon yetersiz; hareketler görüntülemeyi bozduğu için ek ilaç yapıldı.

- MRG kalitesi 4: Sedasyon kötü; sedasyon tamamen yetersiz, çekim iptal edildi.

Verilerin analizi SPSS 12.0 programı ile

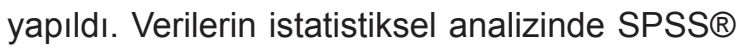
12.0 (SPSS Inc. Chicago, IL, USA) adlı bilgisayar programından yararlanıldı. Veriler ortalama \pm standart deviasyon (SD) olarak, bazı istatistiklerde median değerde hesaplanarak yorumlandı. Testler verilerin normal dağılıma uyup uymamasına göre seçilerek uygulandı. Dağılımı normal olmayan parametreler için non-parametrik testlerden olan Mann Whitney-U testl, değişkenler arası korelasyonu araştırmada ise Spearman korelasyon analizi, eşleştirilmiş gruplar arası farkı belirlemede de Wilcoxon Signed Rank testi uygulandı. Normal dağılıma uyan veriler için iki değişik grup arasındaki farkı belirlemede Student-T testi, eşleştirilmiş gruplar (işlem öncesi ve sonrası) arasındaki farkı belirlemede Paired Samples T testi, değişiklikler arası ilişkileri araştırmada ise Pearson korelasyon analizi uygulandı. Sayımla elde edilen veri grupları farklılığı için Chi-square ve Fischer Exact testi uygulandı. $p<0,05$ olması istatistiksel olarak anlamlı kabul edildi. Çalışma öncesinde lokal etik kuruldan onay alındı.

\section{Bulgular}

Çalışmaya MRG işlemi için sedasyon uygulanan 112 hasta ( $E / K=68 / 44$; \%60/\%39)

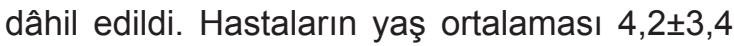
(3 ay-11 yaş) idi. Hastaların 86'sı (\%77) ASA I ve 26‘sı (\%23) ASA II sınıfındaydı. Hastaların ortalama MRG cihazında kalım süresi 20,6 $\pm 5,6$ dakika (1-35) idi. Hastaların 104'üne (\%93) kraniyal MRG, 3'üne (\%3) ekstremite MRG, 3'üne (\%3) lumbosakral MRG, 1'ine (\%1) pelvik MRG ve 1'ine de (\%1) orbital MRG çekimi yapıldı. Sedasyon uygulanan 112 hastadan 8'inin (\%7) çekimi MRG işleminin hemen öncesinde veya işlem sırasında sedasyon yetersizliği nedeniyle iptal edildi. Hastalardan 76'sına (\%68) tek başına 3 hastaya diğer ilaçlarla birlikte kloralhidrat uygulanmıştı. Dokuz hastaya (\%8) sedasyon amacıyla oral yolla meyve suyu içine eklenerek midazolam verilmişti. Yedi hastaya sedasyon için klorpromazin içeren kokteyl uygulanmıştı. On dört (\%12) hastaya tek başına sedasyon amacıyla antihistaminik (difenhidramin) verilmişti. Ketamin uygulanan dört hastanın ikisine ilaç intravenöz ikisine ise intramusküler yolla verilmişti. Kloralhidratın tek başına uygulandığı hastalarda \%20 oranında yetersiz sedasyon tespit edilip, bu hastaların \%6'sının çekimi iptal edilmek zorunda kaldı. Difenhidraminin tek başına verildiği hastalarda sedasyonun başarısızlık oranı \%21 idi ve bu hastaların tümünün çekimleri iptal edilmek zorunda kaldı. Oral yolla midazolam uygulanan 1 hastada (\%11) yetersiz sedasyon izlenip, hastaya ek ilaç dozu uygulanarak hastanın çekimi tamamlandı. Sedatif ilaçlar 81 (\%71) hastada meyve suyu ya da su gibi bir içecek içinde oral, 22 (\%20) hastada intravenöz yoldan uygulandı. İki hastada intramusküler yolla, dört hastada ise rektal yolla ilaç uygulandı. Üç hastada ise ilaçlar iki farklı yoldan (intravenöz ve oral) uygulandı. Hastalardan 19 'una (\%17) uygulanan ilaç ya da ilaçlar yeterli sedasyon oluşturmadığı için ek ilaç dozu uygulanması gerekti.

Sedasyon için ilaç verilen 112 hastadan 22 sinde (\%20) komplikasyon gelişti. Bu komplikasyonlardan en sık görüleni ise 12 (\%54) hastada izlenen bulantı ve kusma gibi gastrointestinal yakınmalardı. İşlemden üç saat sonra kendine gelmeyen ve kolayca uyandırılamayan hastalar aşırı sedasyon olarak kabul edildi ve bu durum $6(\% 27)$ hastada izlendi. İki hastada uyandıktan sonra ajitasyon izlenirken, 2 hastada ise huzursuzluk ve sürekli ağlama görüldü. Tek ilaç verilerek sedatize edilen 104 hastadan 19'unda (\%18) komplikasyon gelişirken birden fazla ilaçla sedatize edilen 8 hastanın 3'ünde (\%37) komplikasyon gelişti. Kloralhidrat verilen bir hastada işlem sonrası hipotermi gelişti. Komplikasyon görülen ve görülmeyen hastalar arasında yaş, ilaç dozu, uyuma süresi, Ramsay Sedasyon Skoru, vital bulgular ve $\mathrm{SO}_{2}$ bakımından istatistiksel anlamda farksız olduğu görüldü $(p>0,05)$. MRG türü ile hastalarda komplikasyon oluşumu arasında ilişki saptanmadı $(p>0,05)$. Kız ve erkek hastalar arasında komplikasyon gelişimi açısından fark izlenmedi $(p>0,05)$. İşlem sonrası $24(\% 21)$ hastada hipoksi ve $7(\% 6)$ hastada ciddi hipoksi izlendi. Hipoksi gelişen hastaların \%66'sı 1 yaş altındaydı. Sedasyon sonrasında hastaların vital bulguları, $\mathrm{SO}_{2}$ ve vücut ısıları arasındaki ilişki Tablo 1'de gösterilmiştir. 
Tablo 1. Sedasyon sonrasında $\mathrm{SO}_{2}$, vücut ISıSı ve vital bulgular arasındaki ilişki.

\begin{tabular}{lllllll}
\hline Değişkenler & $\mathrm{SO}_{2}$ & Vücut ISISI & DKB & SKB & DSS & KTA \\
\hline KTA & $-0,263^{\star \star}$ & $-0,054$ & $-0,562^{\star \star \star}$ & $-0,604^{\star \star \star}$ & $0,787^{\star \star}$ & \\
DSS & $-0,185$ & 0,004 & $-0,460^{\star \star \star}$ & $-0,542^{\star \star \star}$ & \\
Sistolik KB & $0,193^{\star}$ & $-0,009$ & $0,647^{\star \star}$ & & \\
Diastolik KB & 0,066 & 0,139 & & & \\
Vücut ISıSı & $-0,044$ & & & & \\
SO $_{2}$ & & & & & \\
\hline
\end{tabular}

DKB: diastolik kan basıncı, SKB: sistolik kan basıncı, KTA: dakikadaki kalp tepe atımı sayıSı,

DSS: dakikadaki solunum sayısı, $\mathrm{SO}_{2}$ : periferik oksijen satürasyonu

${ }^{*} p<0,05{ }^{* *} p<0,01{ }^{* * *} p<0,001$

Uygulanan ilaç dozu ile MRG kalitesi $(p<0,05)$ ve Ramsay Sedasyon Skoru arasında anlamlı pozitif korelasyon bulundu $(r=0,709$, $p<0,001)$. Verilen ilaç dozu ile hastaların uyuma süresi arasında istatistiksel olarak anlamlı negatif korelasyon bulundu $(r=-0,407, p<0,001)$. MRG kalitesi, ilaç dozu, sedasyon skoru ve çeşitli değişkenler arasındaki ilişkisi Tablo 2'de gösterilmiştir.

Tablo 2. MRG, Sedasyon ve farklı değişkenler arasındaki ilişkisi.

\begin{tabular}{|c|c|c|c|c|c|c|c|}
\hline Değiş̧kenler & $\begin{array}{l}\text { MRG } \\
\text { kalitesi }\end{array}$ & $\begin{array}{l}\text { Ramsay } \\
\text { skoru }\end{array}$ & Yaş & $\begin{array}{l}\text { İlaç } \\
\text { dozu^ }\end{array}$ & MRG süresi & $\begin{array}{l}\text { Ağırlık } \\
\text { pers. }\end{array}$ & $\begin{array}{l}\text { Uyuma } \\
\text { süresi }\end{array}$ \\
\hline MRG kalitesi & & $0,709^{* \star *}$ & 0,119 & $0,221^{*}$ & $-0,400^{\star \star \star}$ & 0,118 & $0,271^{\star *}$ \\
\hline Ramsay skoru & & & 0,072 & 0,083 & $0,453^{\star \star \star}$ & 0,018 & $-0,233^{*}$ \\
\hline Yaş & & & & $-0,061$ & 0,133 & $0,272^{\star *}$ & 0,123 \\
\hline İlaç dozu & & & & & $-0,164$ & $-0,151$ & $-0,407^{* * *}$ \\
\hline MRG süresi & & & & & & 0,154 & $-0,082$ \\
\hline Ağırlık pers. & & & & & & & 0,079 \\
\hline Uyuma süresi & & & & & & & \\
\hline
\end{tabular}

${ }^{*} p<0,05{ }^{* *} p<0,01{ }^{* * *} p<0,001$

$\wedge$ Oral uygulanan kloralhidrat dozu üzerinden hesaplanmıştır.

MRG: Manyetik rezonans görüntüleme 


\section{Tartışma}

Manyetik rezonans görüntülemenin kapalı ve yüksek gürültülü bir ortamda yapılması hasta ve hekim için çeşitli zorlukları da beraberinde getirmektedir. Sedatize edilmiş ve monitorizasyonu istenen şekilde yapılamamış bir hastaya acil bir durumda yapılacak müdahalenin gecikmesi, hasta için hayati sonuçlara yol açabileceği gibi hekim içinde hem tıbbi hem de hukuki açıdan büyük sorumluluklar doğuracaktır. Yetersiz sedasyon nedeniyle MRG sırasında yaşanan güçlükler ve MRG'nin tekrarlanması maliyeti artırmakta ve aletin verimliliğini azaltmaktadır [2]. Çalışmamızda MRG için sedasyon yapılan çocuklarda antihistaminik ilaçların etkisiz olduğu görüldü. Kloralhidratın da en sık kullanılan ajan olmasına rağmen sedasyon için gereken dozunun ayarlanmasındaki güçlükler nedeniyle \%20 oranında yetersiz sedasyon yaptığı saptandı. Çalışmamızda sedasyon yapılan her 5 hastadan birinde komplikasyon görülmüştür. MRG yapılmak üzere sedatize edilen ve MR ünitesine getirilen hastalarımızdan 8'inde (\%7) hastaların işlem için yetersiz sedasyon aldıkları tespit edilip çekimleri iptal edilmişti. Sedasyon ile ilişkili en yaygın komplikasyonun gastrointestinal yakınmalar olması ilaçlara bağlı aspirasyon riskini de ortaya koymaktaydı. MRG ile ilgili sedasyonda en sık görülen istenmeyen etkinin \%5-15 oranında görülen yetersiz sedasyon olduğu bunun da işlemlerin \%3,7'sinde başarısızlığa neden olduğu saptanmıştır [2, 3]. Güncel bir çalışmada MRG için anestezi alan çocuklarda hipotermi riskinin arttığı gösterilmiş olmasına rağmen çalışmamızda sadece bir hastada hipotermi görüldü. Çalışma prosedürlerinin farklı olması ve sedasyon yerine anestezik kullanımının bu duruma yol açtığı düşünüldü [9]. Green ve ark. [10] yaptığı çalışmada ketamin uygulanan 1022 hastada geçici apne, respiratuar depresyon ya da laringospazm gibi yan etkilerin sırasıyla \%0,3 ve $\% 0,4$ oranında olduğu saptanmıştır. Ketamin alan hastalarımızdan ise sadece birinde işlem sonrası huzursuzluk ve sürekli ağlama dışında yan etki izlenmemiştir. İlaçların uygulanış yollarına göre komplikasyon oranı Ruess ve ark. [11] tarafından yapılan bir çalışmada PO uygulama için \%3 için IV uygulama için \%3,2 olarak bulunmuştur. Hastalarımızda PO uygulama için komplikasyon oranı \%11 olarak izlenirken iV uygulama için \%5 olarak tespit edildi. Sanborn ve ark. [12] tarafından sedasyon uygulanan 16467 hasta üzerinde yapılan çok sayıda sedatiflerin uygulandığı bir çalışmada ise solunum sistemini ilgilendiren ciddi komplikasyon oranı $\% 0,4$ olarak bulunmuştur. Hastalarda ciddi kardiovasküler komplikasyon ise izlenmemiştir. Sedasyon için antihistaminiklerin kullanımı etkinliklerinin de düşük olması nedeniyle pediatrik hastalarda önerilmemekle birlikte, anestezist olmayan hekimler tarafından kısa süreli işlemler için kullanılmaktadır [13]. Çalışmamızda da antihistaminik ilaç alan hastaların büyük çoğunluğunda sedasyon yetersiz kalmış ve ek ilaçlar uygulanması gerekmiştir. Hastalarımızın hiçbirinde sıvı, ilaç tedavisi ya da müdahale gerektirecek ciddi kardiyovasküler komplikasyon izlenmemiştir. Malviya ve ark. [14] tarafından yapılan bir çalışmada solunum sistemini ilgilendiren komplikasyon oranının tüm çocuklarda \%5,5 oranında görülürken 1 yaş altı bebeklerde bu oranın \%10 olduğu bildirilmiştir. Ayrıca ASA III hastalar, erken doğum öyküsü olanlar, gastroözofageal reflüsü olan çocuklar ile konjenital kalp hastalığı olan çocukların sedasyon sonrası entübasyon riskinin arttığı gösterilmiştir [15]. Çalışmamızda oksijen saturasyonunda düşüklük görülen hastaların \%66'sının bir yaş altında bebeklerden oluşması bu çalışmanın ortaya attığı tezin doğruluğunu göstermektedir. Çalışmamızın en önemli kısıtlılığını MR işlemisırasında monitorizasyonun devam ettirilememesidir. Ayrıca sedasyon için kullanılan ajanların çeşitliliği ve sedasyonun derinliğini gösteren bispektral indeks ölçümü yapılamaması da çalışmanın diğer kısıtlılıkları arasındadır.

Sonuç olarak, MRG için sedasyon uygulanan hastalarda çoklu ilaç kullanılması komplikasyon oranını artırmaktadır. Özellikle bir yaşın altındaki hastalarda MRG sedasyonuna bağlı olarak hipoksi diğer yaş grubundaki hastalara oranla daha yaygın görülmektedir. Oral yolla uygulanan sedatif ajanların gastrointestinal irritasyon yapıcı yan etkileri nedeniyle hastalarda aspirasyonu kolaylaştırabileceği akılda tutulmalıdır. Antihistaminiklerin MRG'de sedasyon için uygulanması etkisiz bulunmuştur.

Çıkar ilişkisi: Yazarlar bu yazının hazırlanması ve yayınlanması aşamasında herhangi bir çıkar çatışması olmadığını beyan etmişlerdir. 


\section{Kaynaklar}

1. Wheeler DS, Jensen RA, Poss WB. A randomized, blinded comparison of chloral hydrate and midazolam sedation in children undergoing echocardiography. Clin Pediatr 2001;40:381-387. https://doi. org/10.1177/000992280104000704

2. Hubbard AM, Markowitz RI, Kimmel B, Kroger M, Bartko MB. Sedation for pediatric patients undergoing $C T$ and MRG. J Comput Assist Tomogr 1992;16:3-6. https:// doi.org/10.1097/00004728-199201000-00002

3. Malviya S, Voepel-Lewis T, Eldevik OP, Rockwell DT, Wong JH, Tait AR. Sedation and general anaesthesia in children undergoing MRG and CT:adverse events and outcomes. Br J Anaesth 2000;84:743-748. https:// doi.org/10.1093/oxfordjournals.bja.a013586

4. Burk NS. Anesthesia for magnetic resonance imaging. Anesth Clin North Am 1989;7:707-721.

5. Sury MR, Smith JH. Deep sedation and minimal anesthesia. Paediatr Anaesth 2008;18:18-24. https:// doi.org/10.1111/j.1460-9592.2007.02379.x

6. Bracken J, Heaslip I, Ryan S. Chloralhydrate sedation in radiology: retrospective audit of reduced dose. Pediatr Radiol 2012;42:349-354. https://doi.org/10.1007/ s00247-011-2279-9

7. Wolters $U$, Wolf $T$, Stutzer $H$, Schroder T. ASA classification and perioperative variables as predictors of postoperative outcome. Br J Anaesth 1996;77:217222. https://doi.org/10.1093/bja/77.2.217

8. Ramsay MA, Savege TM, Simpson BR, Goodwin R. Controlled sedation with alphaxalone-alphadolone. Br Med J 1974;2:656-659. https://doi.org/10.1136/ bmj.2.5920.656

9. Uludağ, Ö, Kaya R, Tutak A, Doğukan M, Çelik $M$, Dumlupınar E. Effect of anesthesia applied for magnetic resonance imaging on the body temperature of pediatric patients. Cureus 2019;11:e5705. https:// doi.org/10.7759/cureus.5705

10. Green SM, Klooster M, Harris T, Lynch EL, Rothrock SG. Ketamine sedation for pediatric gastroenterology procedures. J Pediatr Gastroenterol Nutr 2001;32:2633. https://doi.org/10.1097/00005176-20010100000010

11. Ruess L, O'Connor SC, Mikita CP, Creamer KM. Sedation for pediatric diagnostic imaging: use of pediatric and nursing resources as an alternative to a radiology department sedation team. Pediatr Radiol 2002;32:505-510. https://doi.org/10.1007/s00247-0020712-9

12. Sanborn PA, Michna E, Zurakowski D, et al. Adverse cardiovascular and respiratory events during sedation of pediatric patients for imaging examinations. Radiology 2005;237:288-294. https://doi.org/10.1148/ radiol.2371041415
13. Olacke B, Nelson T, Sarvas E, Scott JM. A retrospective study of dosing weight and outcomes for one pediatric dental sedation regimen. Pediatr Dent 2018;40:346351.

14. Malviya S, Voepel-Lewis T, Tait AR. Adverse events and risk factors associated with the sedation of children by nonanesthesiologists. Anesth Analg 1997;85:12071213. https://doi.org/10.1097/00000539-19971200000005

15. Kim D, Lee EK, Jeong JS, Gil NS, Hahm TS, Shin $\mathrm{YH}$. Incidence and risk factors of unplanned intubation during pediatric sedation for MRI. J Magn Reson Imaging 2019;49:1053-1061. https://doi.org/10.1002/ jmri.26314

Teşekkür: Teşekkür: Dicle Üniversitesi Tıp Fakültesi Çocuk Sağlığı ve Hastalıkları Anabilim Dalı'nda yürütülen bu tez araştırmasına destek olan Radyoloji Anabilim Dalı teknisyen ve doktorlarına teşekkür ederiz. Araştımanın yürütülmesi için maddi destek ve yardım alınmamıştır.

Etik onayı: Etik Kurul onayı alınmıştır. 